\title{
Convection from Hemispherical and Conical Model Ice Roughness Elements in Stagnation Region Flows
}

\author{
Michael T. Hughes ${ }^{1}$, Timothy A. Shannon ${ }^{2}$, and Stephen T. McClain ${ }^{3}$ \\ Baylor University, Waco, TX, 76798 \\ Mario Vargas ${ }^{4}$ and Andy Broeren ${ }^{5}$ \\ NASA Glenn Research Center, Cleveland, OH, 44135
}

\begin{abstract}
To improve ice accretion prediction codes, more data regarding ice roughness and its effects on convective heat transfer are required. The Vertical Icing Studies Tunnel (VIST) at NASA Glenn Research was used to model realistic ice roughness in the stagnation region of a NACA 0012 airfoil. In the VIST, a test plate representing the leading $2 \%$ chord of the airfoil was subjected to flows of $7.62 \mathrm{~m} / \mathrm{s}(25 \mathrm{ft} / \mathrm{s}), 12.19 \mathrm{~m} / \mathrm{s}(40 \mathrm{ft} / \mathrm{s})$, and $16.76 \mathrm{~m} / \mathrm{s}(55 \mathrm{ft} / \mathrm{s})$. The test plate was fitted with multiple surfaces or sets of roughness panels, each with a different representation of ice roughness. The sets of roughness panels were constructed using two element distribution patterns that were created based on a laser scan of an iced airfoil acquired in the Icing Research Tunnel at NASA Glenn. For both roughness patterns, surfaces were constructed using plastic hemispherical elements, plastic conical elements, and aluminum conical elements. Infrared surface thermometry data from tests run in the VIST were used to calculate area averaged heat transfer coefficient values. The values from the roughness surfaces were compared to the smooth control surface, showing convective enhancement as high as $400 \%$ in some cases. The data gathered during this study will ultimately be used to improve the physical modeling in LEWICE or other ice accretion codes and produce predictions of in-flight ice accretion on aircraft surfaces with greater confidence.
\end{abstract}

\section{Nomenclature}

$\begin{array}{ll}A_{c} & =\text { Accumulation parameter } \\ A_{p} & =\text { Total area of heated section } \\ B & =\text { Systematic uncertainty (Bias) } \\ c & =\text { Chord length } \\ c_{p} & =\text { Specific heat } \\ E & =\text { Voltage across gold-deposited Mylar heater } \\ F z & =\text { Frossling number } \\ h & =\text { Local convective heat transfer coefficient } \\ I & =\text { Current through gold-deposited Mylar heater } \\ k & =\text { Roughness element height } \\ k_{p} & =\text { Thermal conductivity of Plexiglas }\left(=0.205 \mathrm{~W} / \mathrm{m}^{*} \mathrm{~K}\right) \\ k_{f} & =\text { Thermal conductivity of a fluid } \\ L W C & =\text { Liquid water content } \\ M V D & =\text { Mean volumetric diameter of water droplets in icing event } \\ N & =\text { Number of repeated measurements used to calculate a mean measurement } \\ N u & =\text { Nusselt number }\end{array}$

${ }^{1}$ Graduate Assistant, Department of Mechanical Engineering, One Bear Place \#97356, AIAA Student Member.

${ }^{2}$ Graduate Assistant, Department of Mechanical Engineering, One Bear Place \#97356, AIAA Student Member.

${ }^{3}$ Associate Professor, Department of Mechanical Engineering, One Bear Place \#97356, AIAA Senior Member.

${ }^{4}$ Aerospace Engineer, Icing Branch, 21000 Brookpark Rd., AIAA Associate Fellow.

${ }^{5}$ Aerospace Engineer, Icing Branch, 21000 Brookpark Rd., AIAA Associate Fellow. 


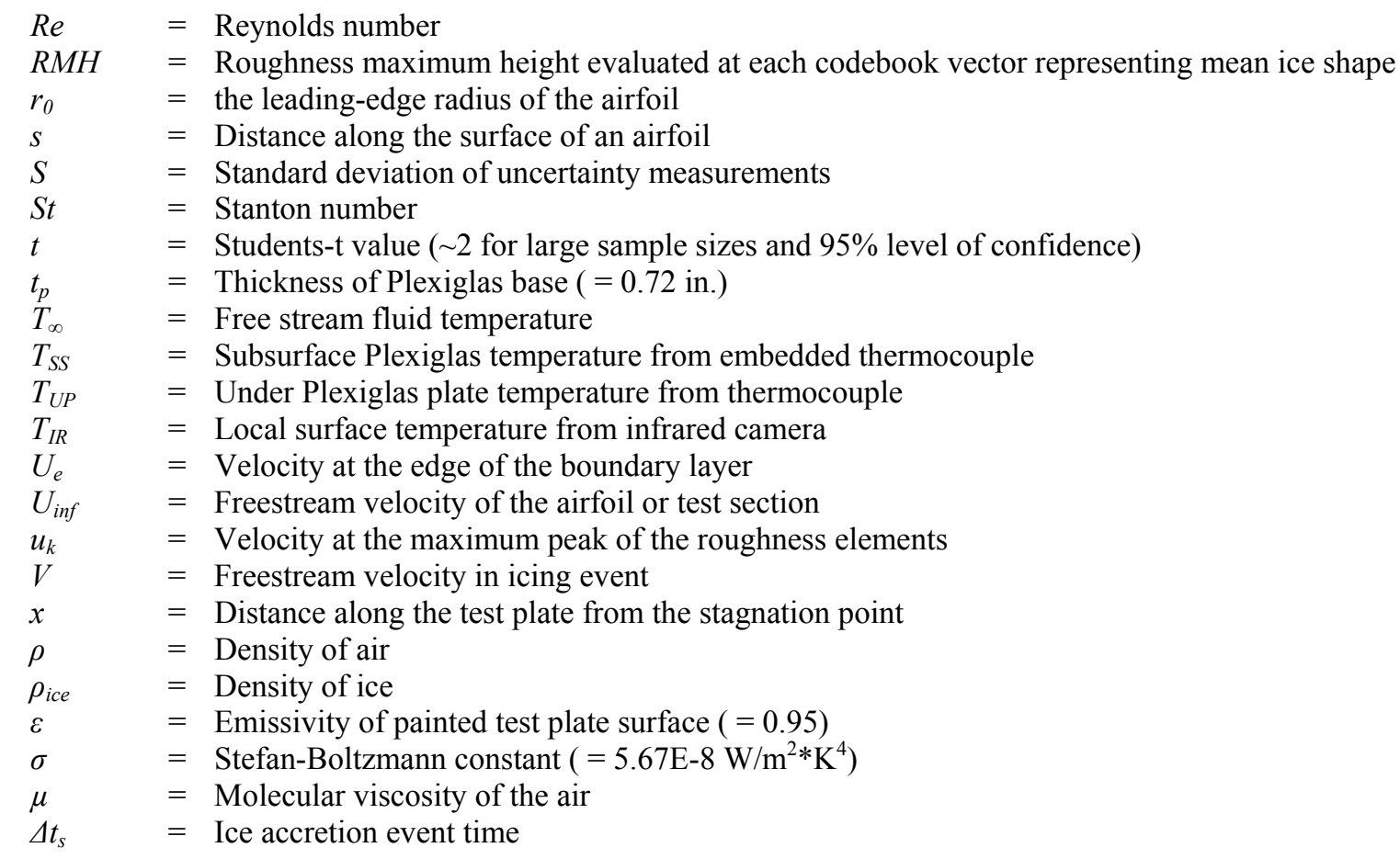

\section{Introduction}

T EWICE couples computational fluid dynamics, heat transfer, droplet capture physics, and solidification thermodynamics to predict the formation of ice accretions on airfoils. Because of the importance of removing latent energy from liquid layers found in glaze icing conditions to enable phase change of the water to ice, capturing the convective enhancement of roughness elements formed on the iced airfoil surface is critical to in-flight ice accretion predictions in supercooled droplet conditions. However, the sand-grain equivalent model, used by LEWICE to model ice roughness, is generated by a single variable, the freezing fraction at the stagnation point which describes how rapidly ice will freeze following its impingement on the airfoil [1]. Further, the correlations used in LEWICE to predict the convective heat transfer are based on ordered arrays of deterministic elements [1, 2]. Because of its use of a simplified roughness and convection enhancement models, LEWICE predictions of the convection losses from the airfoil, while currently conservative from a vehicle design and safety standpoint, can be improved.

In improving the LEWICE roughness and convection models, it is important to recognize the significant differences between real ice roughness and the roughness employed in most historic literature regarding flow over and convection rough surfaces. As most recently noted by Shannon and McClain [3], realistic ice roughness varies greatly from classical roughness correlations such as the sand grain equivalent model used in LEWICE. The ways in which they vary are as follows:

1) Rather than a uniform grid or pattern, real ice roughness displays a random distribution in both element size and location on the surface on which it accretes,

2) Ice roughness elements exhibit a wide variety of shapes most of which are not readily described using deterministic geometry,

3) Ice roughness properties vary in the direction of flow and may even exhibit an abrupt smooth-to-rough transition,

4) Surfaces with ice roughness exhibit varying thermal boundary conditions in the direction of flow due to the variations in ice growth rates,

5) Because of the nature of an airfoil, surfaces undergoing ice accretion experience mild to high flow acceleration, and

6) Because of the local freezing process, the surface of the ice roughness is essentially isothermal and acts as a surface with near infinite thermal conductivity. 
Previous studies in this series have examined various cases of ice roughness in order to isolate the importance of the realistic ice roughness features noted above related to the enhancement of convective heat transfer during icing events. Tecson and McClain [4] studied convective enhancement of surfaces exposed to flows with minimal freestream acceleration with random element distributions similar to those found in real icing events. Walker et al. [5] continued the study by observing the same surfaces in flows with minimal freestream acceleration but which were exposed to changing thermal boundary conditions. Shannon and McClain [3] furthered the series of studies by adding new surfaces which modeled IRT icing events and exposing both the previous surfaces and the new IRT surfaces to accelerating flows with both constant and varying thermal boundary conditions. Shannon and McClain [3] used the IRT surfaces to model the leading $17.1 \%$ chord of a NACA 0012 airfoil exposed to a short-duration icing event. However, due to the limitations of the accelerating flow insert and wind tunnel used in the experiment, the rapid acceleration in the stagnation region, the leading $2 \%$ chord region, of the NACA 0012 airfoil was not replicated. For the ice roughness case explored by Shannon and McClain [3], the accretion time and resulting accumulation parameter, defined as:

$$
A_{c}=\frac{L W C \cdot V \cdot \Delta t_{s}}{2 \cdot r_{0} \cdot \rho_{\text {ice }}}
$$

are low enough $\left(A_{c} \approx 0.2\right)$ that roughness is not substantial in the stagnation region. That is, the roughness levels in the stagnation region are not large enough to force premature transition or elevated convective heat transfer rates beyond those of laminar stagnation region flow.

For longer accretion times, when $A_{c}$ approaches values of 0.5 and higher [6-8], significant roughness features develop in the stagnation region. After $A_{c}$ values approach 0.5 , the leading $2 \%$ region becomes critical to the study ice accretion heat transfer because the roughness elements may cause the flow to transition to turbulent even in the presence of the very high flow acceleration rates. The efforts of this paper were performed to examine the leading $2 \%$ chord mentioned above and further the study of ice roughness and its enhancement of convective heat transfer in icing events once significant roughness has developed in the stagnation flow region of the airfoil. To accomplish this, a heated test plate was installed in the Vertical Icing Studies Tunnel (VIST) at NASA Glenn Research Center. Roughness panels exhibiting characteristics matching those of a 21 in. NACA 0012 airfoil exposed to a short duration icing event were created for installation on the VIST heated test plate. The test plate, outfitted with the roughness panels, was heated and exposed to various flow situations. Surface temperatures were measured using an infrared camera and combined with thermocouple data to determine the conduction, convection, and radiation losses from the heated test plate during steady state conditions. From the data, local convection coefficients were calculated and compared to surface panels with no roughness, representing an airfoil with no ice accretions; thus giving quantifiable enhancement of the convective heat transfer due to ice roughness.

In Hughes et al. [9], the initial convection maps from the surfaces with plastic hemispherical elements and the results of a flow quality study were presented. In the present paper, the local non-dimensional convection coefficients are compared to historical studies of airfoil stagnation region heat transfer for smooth surfaces. Further, surfaces with plastic cones and surfaces with aluminum cones were added to the VIST investigations. The conical elements were created with the same distributions as the hemispherical elements and were used to investigate the importance of the roughness element shape in determining the convection coefficients. The aluminum surfaces were created to investigate the effects of the constant freezing temperature of the freezing front on the ice surfaces. Because of the very high thermal conductivity, the aluminum surfaces create a near isothermal surface replicating the isothermal surface icing condition. While testing surfaces constructed using Aluminum hemispheres was initially desired, hemispherical elements could not be satisfactorily machined for the study because of the finite mill tool diameters in combination with the very close proximities of the elements on the distributions employed.

\section{Methodology}

All testing in this study was performed at NASA Glenn Research Center using the Vertical Icing Studies Tunnel (VIST). The following sections will outline the testing apparatus, the creation of the test plate, the scaling and creation of the surface panels, the testing procedure and test cases, and the data reduction approach used.

\section{A. Testing Apparatus}

The VIST is a closed loop, atmospheric tunnel with a 7.2:1 contraction ratio, a 4 in. wide throat, and a 3 HP DC motor with a max speed of $1750 \mathrm{rpm}$. The VIST's fan enables throat velocities up to $25 \mathrm{~m} / \mathrm{s}(82 \mathrm{ft} / \mathrm{s})$. The VIST was 
designed in 2005 by White and Oliver [10]. The VIST was originally design to study water droplet impingement in the stagnation region of a mid-sized commercial jet airliner.

The VIST's design to study the stagnation region of airfoils made it an ideal testing apparatus for this investigation of icing heat transfer. Unlike conventional wind tunnels, the VIST utilizes an instrumented flat plate to model the airfoil desired. To model the stagnation region of the desired airfoil, the side walls of the VIST were contoured and instrumented with pressure taps to ensure the test plate was subjected to the same accelerating flows experienced by the airfoil in question. The original test plate installed in the VIST was a $30 \mathrm{in}$. by 60 in. flat, aluminum plate instrumented with pressure taps along its surface. The stagnation point on the test plate was directly in the center, with the flow impinging downward on the test plate at the center and accelerating as the flow continued outward as shown in Figure 1. For this study, new side walls were created to subject the test plate to flows experienced by a NACA 0012 and to allow infrared camera access as shown in Figure 2. Additionally, a new test plate was created for the heat transfer experiments used in this study.

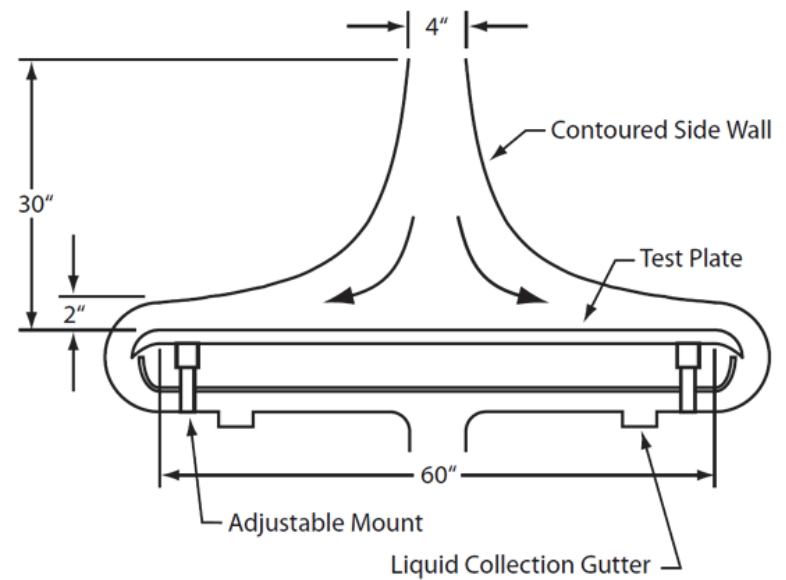

Figure 1. VIST Schematic Showing Side Wall and Test Plate Position [Reprinted from White and Oliver [10] with permission]

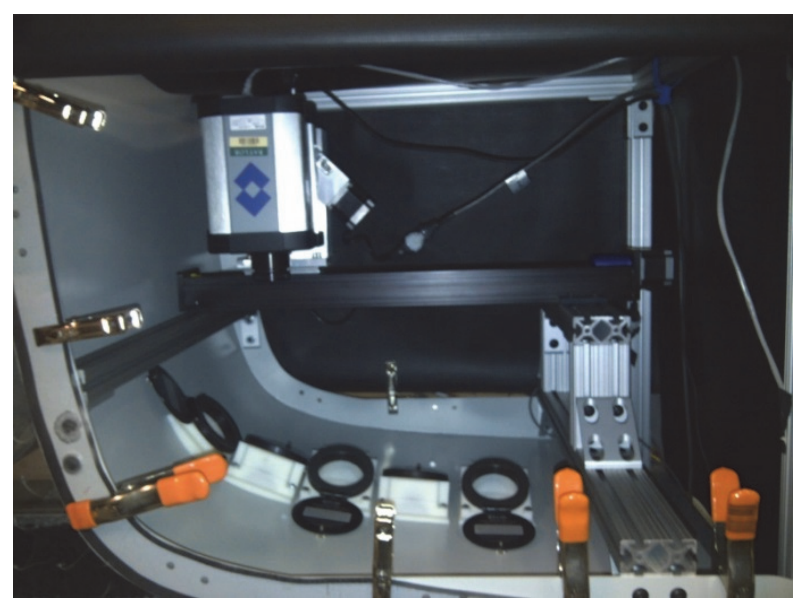

Figure 2. VIST Side Wall Showing Camera Mount Location and IR Viewports

\section{B. Test Plate}

The original test plate for the VIST was instrumented to study pressure variation along the plate and allow for hotwire and pitot-probe traces, but since this study examined heat transfer, a new test plate was needed to allow for heat transfer measurements. The new heated test plate consisted of 4 layers as shown in Figure 3. A Plexiglas base, with a thickness of 0.72 in., was selected to provide the test plate with a low conductivity surface to minimize heat loss. A gold-deposited Mylar film heater, measuring 7 in. by 20.5625 in., was placed in the center of the test section to provide heat during the steady state tests. The surface panels were placed on top of the heated, or the Plexiglas base on areas not covered by the heater, and consisted of two layers. The bottom layer was constructed of Neoprene to even out the contact pressure between the panels and the heater elements. The second layer consisted of the surface itself, containing either a smooth finish or roughness elements and made of either ABS plastic or aluminum. While the Plexiglas surface was far less conductive than an aluminum one, conduction losses through the base still needed to be quantified for the experiment. To accomplish this, several K-type thermocouples were placed throughout the test plate. Beginning at the stagnation point and continuing in the streamwise direction, 14 thermocouples were placed just under the heater, as shown in Figure 4, and are referred to as the Sub-Surface Thermocouples. An additional 10 thermocouples were placed on the bottom of the Plexiglas base at the same locations as the first 10 Sub-Surface Thermocouples and are referred to as the Under-Plate Thermocouples. 


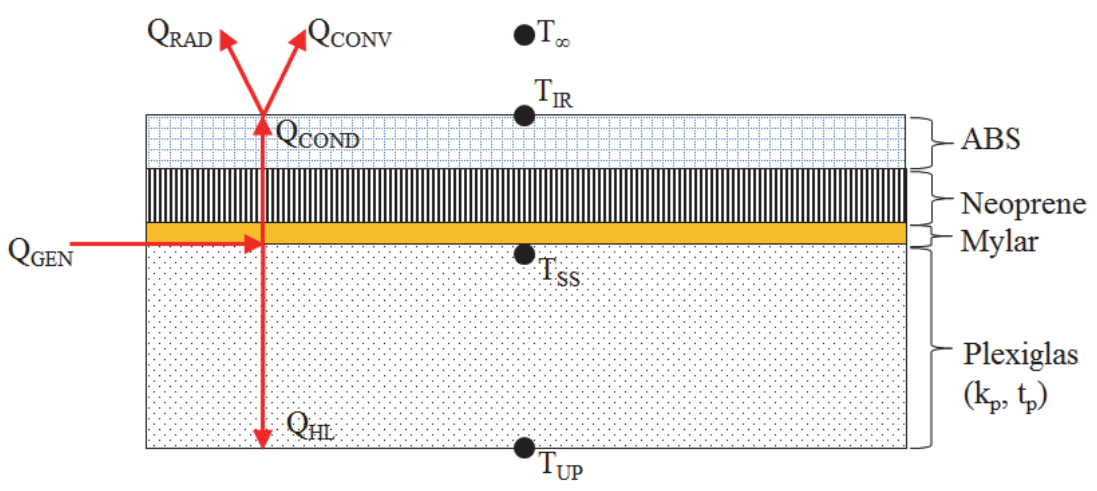

Figure 3. Heated test plate cut-away showing different layers of the plate. [Reprinted from Walker et al. [5] with permission]

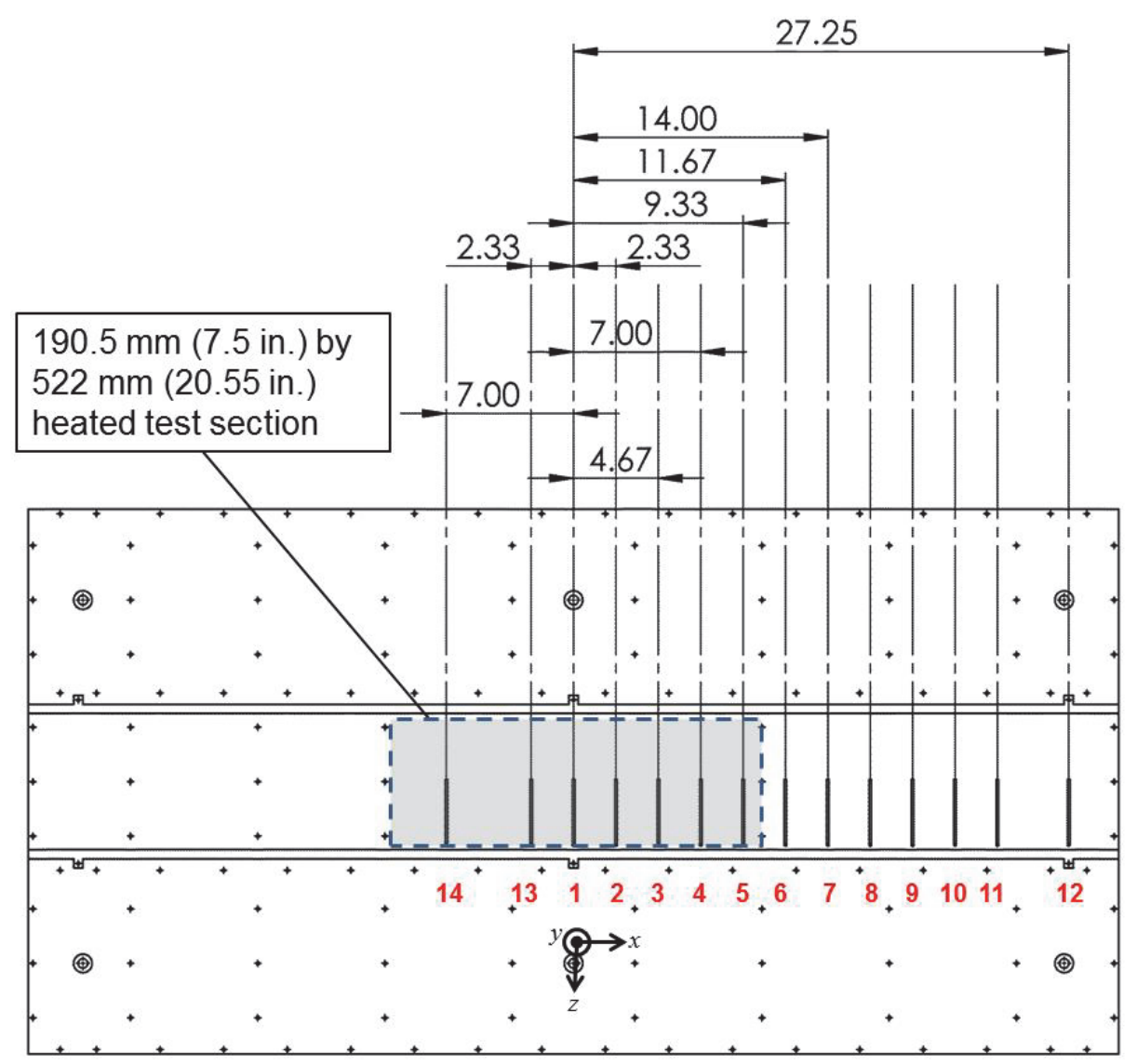

Figure 4. Layout of heated test plate showing thermocouple locations and location of Gold-deposited Mylar film heater.

\section{Surface Panels}

The roughness models used in this experiment were based on an IRT icing event on a $21 \mathrm{in}$. NACA 0012 with the characteristics shown in Table 1. Due to the size difference between the $21 \mathrm{in.} \mathrm{NACA} 0012$ and the 30 in by 60 in test section in the VIST, the modeled surfaces needed to be scaled. The leading $2 \%$ chord of the $21 \mathrm{in}$. NACA 0012 was measured at \pm 0.42 in. from the stagnation region. Scaling this to the VIST test section, \pm 30 in., to match Reynolds numbers in both the streamwise velocity, Eq. (1), and velocity at the maximum height roughness elements, Eq. (2), resulted in a throat velocity of $0.93 \mathrm{~m} / \mathrm{s}(3 \mathrm{ft} / \mathrm{s})$ which was outside of the VIST's operational range. 


$$
\begin{gathered}
\operatorname{Re}_{x}=\left.\frac{\rho U_{e} x}{\mu}\right|_{\text {Plate }}=\left.\frac{\rho U_{e} s}{\mu}\right|_{\substack{N A C A \\
0012}} \text {. } \\
\operatorname{Re}_{k}=\left.\frac{\rho u_{k} k}{\mu}\right|_{\text {Plate }}=\left.\frac{\rho u_{k} k}{\mu}\right|_{0012} ^{N A C A}
\end{gathered}
$$

Therefore, using the entire test section of the VIST was not practical. To remedy this, only the center section of the test plate was utilized; that is, \pm 10.27 in. from the stagnation region. This resulted in a geometric scaling factor of 25 when compared to the $2 \%$ chord ( \pm 0.42 in.) of the NACA 0012 . However, scaling the individual roughness elements by 25 resulted in a maximum element height of $25 \mathrm{~mm}(\approx 1 \mathrm{in}$.) and a maximum element diameter of $50 \mathrm{~mm}(\approx 2 \mathrm{in}$.). Elements of this sized caused another problem: when viewed with the infrared camera, the largest elements would occupy a large portion of the IR image, resulting in poor values for local heat transfer coefficients which would not represent a spatially averaged heat transfer coefficient.

\section{Table 1. Characteristics of icing event used to determine roughness distribution in test panels} (IRT test case 032714.06)

\begin{tabular}{|c|c|}
\hline Airfoil & 21 in. NACA 0012 \\
\hline MVD & $29.7 \mu \mathrm{m}$ \\
\hline LWC & $0.6 \mathrm{gm} / \mathrm{m}^{3}$ \\
\hline Freezing Fraction & 0.217 \\
\hline$\Delta \mathbf{t}_{\mathbf{s}}$ & $200 \mathrm{~seconds}$ \\
\hline $\mathbf{V}$ & $66.7 \mathrm{~m} / \mathrm{s}$ \\
\hline $\mathbf{A}_{\mathbf{c}}$ & 0.521 \\
\hline
\end{tabular}

Another option was to choose a geometric scaling factor of 10 , resulting in the leading $2 \%$ chord region of width $\pm 107 \mathrm{~mm}$ ( $\pm 4.2 \mathrm{in}$.). However, this resulted in a throat velocity requirement of $21 \mathrm{~m} / \mathrm{s}(67 \mathrm{ft} / \mathrm{s})$ which was near the upper limit of the VIST's operational range. Additionally, operating at high velocities would result in much higher convection losses from the heated test plate, reducing the temperature difference between the freestream and the test plate surface and making the measurements more difficult.

Because the geometric scaling factors of 10 and 25 were both feasible but presented problems, a combination of the two was decided upon. Two schemes were devised. The first scheme was a geometric scaling of both the roughness elements and the leading $2 \%$ chord region by a factor of 10 . This was known as the $\times 10 \times 10$ surface. The second scheme was a geometric scaling of the roughness elements by a factor of 10 and the leading $2 \%$ chord region by a factor of 25 . This was known as the $\mathrm{x} 10 \times 25$ surface. However, due to this compromise, Reynolds numbers on these schemes did not match the IRT test from which the roughness surfaces were created. To remedy this, three throat velocities were selected to provide an "envelope" around the desired Reynolds scaling. The velocities were $7.62 \mathrm{~m} / \mathrm{s}(25 \mathrm{ft} / \mathrm{s}), 12.19 \mathrm{~m} / \mathrm{s}(40 \mathrm{ft} / \mathrm{s})$, and $16.76 \mathrm{~m} / \mathrm{s}(55 \mathrm{ft} / \mathrm{s})$. Table 2 contains a summary of characteristics from each of the velocity cases and compares them to the NACA 0012 from which the roughness surfaces were created.

To model the realistic ice roughness correctly, the distribution of roughness elements and the mean element height in relation to the distance from the stagnation point were obtained from an IRT icing event. The icing event used for the study, identified as IRT test case 032714.06 and summarized in Table 1, was scanned with a ROMER Absolute Arm laser scanning system. From the resulting point cloud, shown in Figure 5, the method of McClain and Kreeger [11] was used to determine the variations in the roughness in the streamwise direction. From the roughness results, the roughness maximum height, defined as 3.09 times the root-mean-square element height, was determined and plotted as a function of distance from the stagnation point, shown in Figure 6. Using the method employed by Tecson and McClain [12] a LaGrangian droplet simulator was used to generate a roughness element distribution which modeled the maximum roughness height for the 032714.06 case. The blue dashed line of Figure 6 depicts the diameter scaling function, which is a function of the X-distance from the stagnation point and which was multiplied by the local element diameters to create a distribution with same X-direction property variations as exhibited by the 032714.06 case. The resulting distribution containing the same roughness variation modeled using hemispheres and cones as shown in Figure 7. The cones were constructed using a base to height ratio of 0.5 so that the apex height of the cones would be the same as the apex height of the hemispheres. 
With the surface distributions generated, .stl files were created in SolidWorks and used to create plastic and aluminum surfaces. The plastic surface were printed on an Objet 30 3D printer using their VeroWhite Plus material with a resolution of 0.003 -in.. while the aluminum surfaces were generated using a $\mathrm{CNC}$ router. Table 3 displays the various surfaces and scaling factors used, resulting in a total of 7 test surfaces.

Table 2. Summary of Test Case Design Parameters Compared to NACA 0012

\begin{tabular}{|c|c|c|c|c|c|c|c|c|}
\hline $\begin{array}{c}\text { Roughness } \\
\text { Pattern }\end{array}$ & $\begin{array}{c}U_{\text {th }} \text { or } \\
U_{\infty}(\mathrm{m} / \mathrm{s})\end{array}$ & $\begin{array}{c}x_{2 \%} \text { or } s_{2 \%} \\
(\mathrm{~mm})\end{array}$ & $\begin{array}{c}U_{e, 2 \%} \\
(\mathrm{~m} / \mathrm{s})\end{array}$ & $\begin{array}{c}k_{\max , 2 \%} \\
(\mathrm{~mm})\end{array}$ & $\begin{array}{c}\rho \\
\left(\mathrm{kg} / \mathrm{m}^{3)}\right.\end{array}$ & $\begin{array}{c}\mu \times 10^{6} \\
\left(\mathrm{Ns} / \mathrm{m}^{2}\right)\end{array}$ & $R e_{x, 2 \%}$ & $R e_{k, 2 \%}$ \\
\hline $\mathrm{x} 10 \times 10$ & 7.62 & 107 & 2.74 & 10.6 & 1.219 & 18.4 & 19,415 & 1,923 \\
\hline $\mathrm{x} 10 \times 10$ & 12.19 & 107 & 4.38 & 10.6 & 1.219 & 18.4 & 31,059 & 3,077 \\
\hline $\mathrm{x} 10 \times 10$ & 16.76 & 107 & 6.02 & 10.6 & 1.219 & 18.4 & 42,702 & 4,230 \\
\hline $\mathrm{x} 10 \times 25$ & 7.62 & 261 & 4.28 & 10.6 & 1.219 & 18.4 & 73,964 & 3,004 \\
\hline $\mathrm{x} 10 \times 25$ & 12.19 & 261 & 6.84 & 10.6 & 1.219 & 18.4 & 118,322 & 4,805 \\
\hline $\mathrm{x} 10 \times 25$ & 16.76 & 261 & 9.41 & 10.6 & 1.219 & 18.4 & 162,681 & 6,607 \\
\hline Smooth & 7.62 & $\mathrm{n} / \mathrm{a}$ & $\mathrm{n} / \mathrm{a}$ & $\mathrm{n} / \mathrm{a}$ & 1.219 & 18.4 & $\mathrm{n} / \mathrm{a}$ & $\mathrm{n} / \mathrm{a}$ \\
\hline Smooth & 12.19 & $\mathrm{n} / \mathrm{a}$ & $\mathrm{n} / \mathrm{a}$ & $\mathrm{n} / \mathrm{a}$ & 1.219 & 18.4 & $\mathrm{n} / \mathrm{a}$ & $\mathrm{n} / \mathrm{a}$ \\
\hline Smooth & 16.76 & $\mathrm{n} / \mathrm{a}$ & $\mathrm{n} / \mathrm{a}$ & $\mathrm{n} / \mathrm{a}$ & 1.219 & 18.4 & $\mathrm{n} / \mathrm{a}$ & $\mathrm{n} / \mathrm{a}$ \\
\hline $\begin{array}{c}\text { NACA } \\
0012\end{array}$ & 66.7 & 10.7 & 63.8 & 1.15 & 1.306 & 17.2 & 51,978 & 5,586 \\
\hline
\end{tabular}

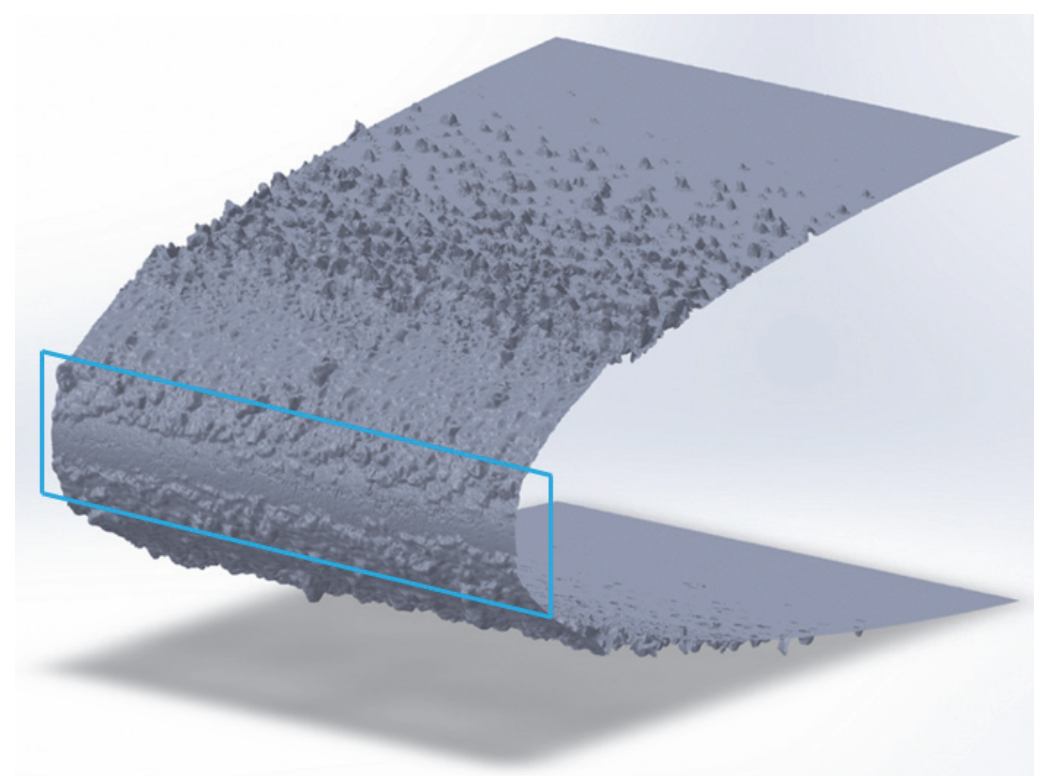

Figure 5. Point cloud from NACA 0012 icing event used to generate roughness panels [9]

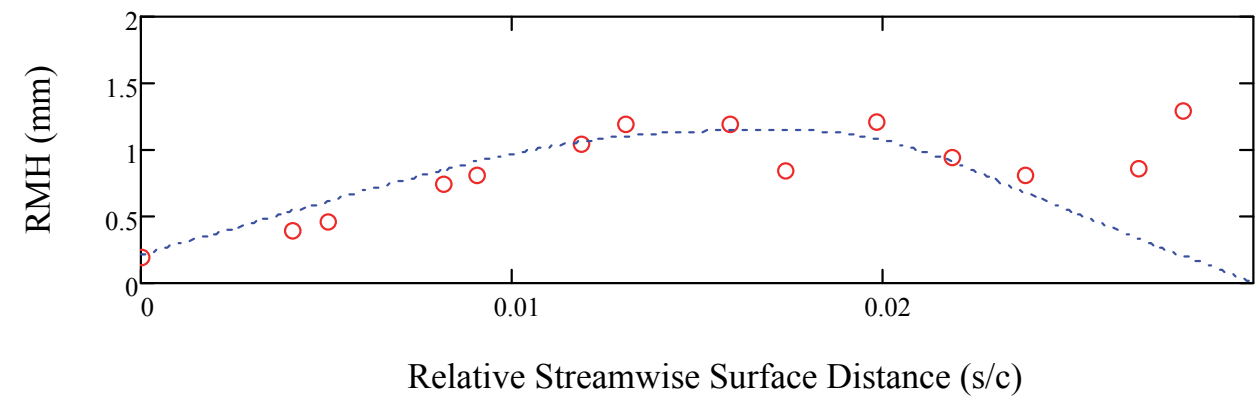

Figure 6. Max roughness height as a function of distance from the stagnation point [9]

American Institute of Aeronautics and Astronautics 


\section{Procedure}

For each experimental test, calibrations were performed to reduce uncertainty and improve the quality of the data collected. The tunnel and test plate with the appropriate surface panels installed were left cold overnight to ensure an equilibrium temperature throughout the testing apparatus. The morning of testing, a LabVIEW software program that was used to run and monitor the VIST was activated and used to record baseline temperature and pressure data. Then, infrared images were recorded at each of the 7 positions for 10 seconds at 10 frames per second. The unheated infrared images provided a baseline surface temperature map, to which the test runs performed following the calibration could be compared. Taking the difference between the test data and the calibration data minimized total uncertainty by substantially reducing the systematic uncertainty of the FLIR camera and the thermocouples placed throughout the test section.

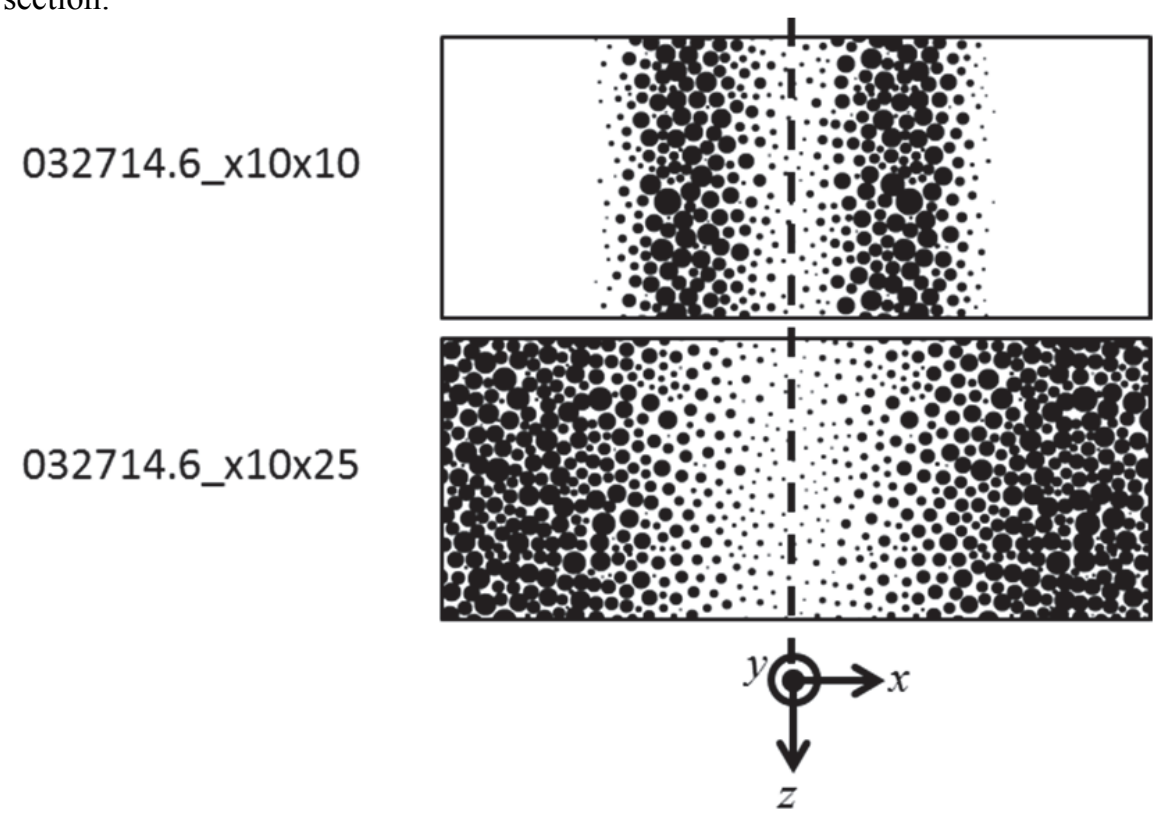

Figure 7. $x 10 \times 10$ and $\times 10 \times 25$ roughness distributions. Both distributions were modeled using hemispheres and cones. [The $\mathrm{X}$-limits of the two surface depictions is $\pm 261 \mathrm{~mm}( \pm 10.27 \mathrm{in}$.$) .]$

Table 3. Roughness panels and layouts.

\begin{tabular}{|c|c|c|}
\hline Surface Distribution & Material & Element Shape \\
\hline $\mathrm{x} 10 \times 10$ & VeroWhite & Hemispheres \\
\hline $\mathrm{x} 10 \times 10$ & VeroWhite & Cones \\
\hline $\mathrm{x} 10 \times 10$ & Aluminum & Cones \\
\hline $\mathrm{x} 10 \times 25$ & VeroWhite & Hemispheres \\
\hline $\mathrm{x} 10 \times 25$ & VeroWhite & Cones \\
\hline x10x25 & Aluminum & Cones \\
\hline Smooth & VeroWhite & No Elements \\
\hline
\end{tabular}

Following calibration, the LabVIEW program was used to select the desired upstream flow velocity and start the tunnel. For each test, the VIST's cooling system was activated and set to $65^{\circ} \mathrm{F}$. The thin-film heater power supply was then activated and set to the desired input current and voltage, which were typically $6 \mathrm{~A}$ and $6 \mathrm{~V}$, respectively. Two multimeters were used to verify the voltage leaving the power supply and the voltage across the thin-film heater throughout the duration of the test. Temperatures throughout the test section were then monitored using the LabVIEW software to determine when the tunnel had achieved steady-state temperatures. The process of reaching steady state typically required two hours. Once the tunnel had achieved stable temperatures, denoting steady state, the infrared camera was used to record images for 10 seconds at 10 frames per second at each of the 7 positions. These recorded images provided a detailed temperature distribution of the test plate surface. The LabVIEW program 
used to operate the tunnel also recorded thermocouple data throughout the duration of the test which was used to determine the conduction and radiation losses.

\section{E. Data Reduction}

Following each test, a large amount of data was gathered. The IR images acquired provided surface temperature data $\left(T_{I R}\right)$, thermocouples in the test plate provided temperature directly below the surfaces $\left(T_{S S}\right)$ and temperature underneath the test plate $\left(T_{U P}\right)$, thermocouples placed in the tunnel provided freestream temperature $\left(T_{\infty}\right)$ which was also used as the temperature of the surroundings, and multimeters supplied the input current (I) and the input voltage (V). From this data and constants determined prior to testing, an energy balance was used to calculate the local convection heat transfer coefficient, $h$, at each pixel location as shown in Eq. (4).

$$
h_{i, j}=\frac{\frac{E I}{A_{p}}-\frac{k_{P}\left(T_{S S}-T_{U P}\right)}{t_{P}}-\sigma \varepsilon\left(T_{I R_{i, j}}^{4}-T_{w}^{4}\right)}{\left(T_{I R_{i, j}}-T_{\infty}\right)}
$$

From the local convection coefficients, 1 -in. by 1 -in. area averaged values, $\bar{h}$, were then determined by taking the area average at each in. from the stagnation region, as shown in Eq. (5).

$$
\bar{h}=\frac{\frac{E I}{A_{p}}-\frac{k_{P}\left(T_{S S}-T_{U P}\right)}{t_{P}}-\sigma \varepsilon\left({\overline{T_{I R}}}^{4}-T_{w}^{4}\right)}{\left(\overline{T_{I R}}-T_{\infty}\right)}
$$

Following the calculation of the heat transfer coefficient values, other non-dimensional correlations were calculated. The Nusselt number with respect to total chord length, $N u$, was calculated using Eq. (6),

$$
\overline{N u}=\frac{\bar{h} c}{k_{f}}
$$

where $k_{f}$ is the thermal conductivity of the fluid, and $c$ is the length of the scaled chord. Stanton numbers with respect to the local Reynolds numbers were found using Eq. (7) and Eq. (8) respectively.

$$
\begin{gathered}
\overline{S t}=\frac{\bar{h}}{\rho c_{p} U_{e}} \\
\operatorname{Re}_{x}=\frac{\rho U_{e} x}{\mu}
\end{gathered}
$$

Finally, the Frossling number, which was used to compare data to previous studies, was found using Eq. (9).

$$
F z=\frac{\overline{N u}}{\sqrt{\operatorname{Re}_{c}}}
$$

Because of the camera location and the contoured side walls, each of the 7 images corresponding to different locations in the streamwise direction had varying real world dimensions and also contained large portions of the tunnel side walls. That is, while each image was 320 pixels by 256 pixels, the number of pixels per in. varied depending on the position and angle of the camera from which the image was taken. From images taken prior to testing, the rate of pixels per in. for each image and its corresponding real world location was calculated and implemented into a MATLAB script. For more details regarding the pixel mapping process, the data acquisition method, and the data reduction approach the reader is referred to Hughes [13]. 


\section{F. Uncertainty Analysis}

Uncertainty calculations for the convective heat transfer values were determined using the large sample size approach of Coleman and Steele [14], which is an extension of the approach of Kline and McClintock [15]. The uncertainties for each experimentally measured quantity used in Eq. (5) are presented in Table 4.

The main benefit of the in situ calibration performed before testing each day was the reduction of the instrument error of the infrared temperature measurements. By taking the difference in between the calibration and test temperature values, the systematic uncertainties in the temperature measurements were all correlated. Thus, systematic uncertainty propagating into the resulting convection coefficients contributed by the temperature measurements was negligible.

Table 4. Uncertainty Values for Convective Heat Transfer Coefficient Measurements

\begin{tabular}{|c|c|c|}
\hline Variable & Systematic Uncertainty & Total Uncertainty \\
\hline$E$ & $B_{E}=0.03 \% E$ & $\sqrt{B_{E}^{2}+\left(\frac{t S_{E}}{\sqrt{N_{E}}}\right)^{2}}$ \\
\hline$I$ & $B_{I}=1.0 \% I$ & $\sqrt{B_{I}^{2}+\left(\frac{t S_{I}}{\sqrt{N_{I}}}\right)^{2}}$ \\
\hline$A_{t}$ & $B_{d}=1 / 32^{\prime \prime}$ & $\sqrt{\left(B_{d} W_{h a}\right)^{2}+\left(B_{d} L_{h a}\right)^{2}}$ \\
\hline$t_{p}$ & $B_{d}=1 / 32^{\prime \prime}$ & $B_{d}$ \\
\hline$T_{I R}$ & $B_{T}=2 \mathrm{~K}$ & 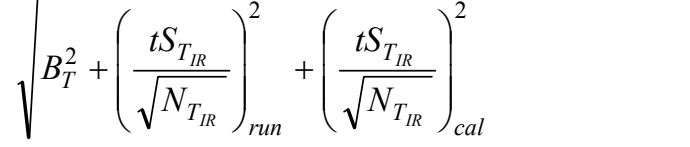 \\
\hline$T_{S S}$ & $B_{T}=2 \mathrm{~K}$ & 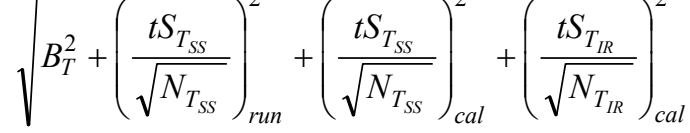 \\
\hline$T_{U P}$ & $B_{T}=2 \mathrm{~K}$ & 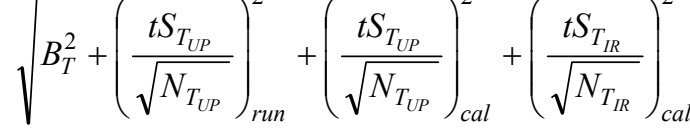 \\
\hline$T_{\infty}$ & $B_{T}=2 \mathrm{~K}$ & 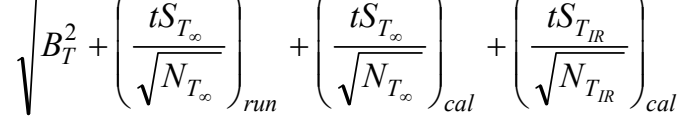 \\
\hline
\end{tabular}

\section{Results and Discussion}

The process of creating detailed convection maps for the surfaces and the flow validation results were covered in Hughes et al. [9]. The results of this study focus on the validation of the convection measurements and the determination of the roughness enhancement for the cases studied. Only reduced measurements are reported in this paper; the reader is directed to Hughes [13] for directly measured experimental quantities and intermediate reduced results.

\section{A. Baseline Comparison to Poinsatte Results}

While significant historical literature exists regarding stagnation region flows, the most relevant to the Reynolds number regime used in this study and the most relevant to in-flight icing are the studies by Poinsatte [16] and Poinsatte et al. [17]. In the Poinsatte investigations, spanwise-strip heaters were installed in a NACA 0012 airfoil and exposed to various conditions in the IRT and in real atmospheric flows using the NASA Twin Otter Icing Research Aircraft. Using a complex control system, the power to each heater was controlled to maintain a constant 
temperature along the airfoil surface. Several distributions of hemispherical roughness were then added to the heated leading-edge area of the airfoil to mimic ice accretion roughness.

While the smooth NACA 0012 airfoil studies of Poinsatte are similar in configuration to the stagnation flow studies in the VIST, finding a case to directly compare results is difficult for several reasons. First, the free stream velocities used by Poinsatte [16] and Poinsatte et al. [17] do not directly match the cases used in this study which were constructed to match more recent icing studies in the IRT. Second, the apparatus employed for the Poinsatte studies was constructed to impose isothermal surface conditions, while the VIST efforts were constructed to reflect constant flux conditions.

In reviewing all of the cases studied by Poinsatte [16] and Poinsatte et al. [17], the most closely related case to the current study was performed in the IRT and resulted in a chord Reynolds number of $2.42 \times 10^{6}$. This case is most appropriately compared to the smooth surface case exposed to a VIST throat velocity of $16.76 \mathrm{~m} / \mathrm{s}(55 \mathrm{ft} / \mathrm{s})$ which when employing a x10 surface scaling would correspond to a chord Reynolds number of $2.25 \times 10^{6}$. Figure 8 presents a comparison of the VIST data to the appropriate Poinsatte data cast in terms of Frossling numbers versus the distance from the stagnation point relative to the airfoil chord, which was the dimensionless formatting of convection results preferred in the Poinsatte studies. The Smith and Spalding [18] prediction, as indicated in Eq. (10), for the isothermal Poinsatte case is also presented.

$$
F z_{c}=\frac{N u_{c}}{\sqrt{\operatorname{Re}_{c}}}=\frac{0.332 \operatorname{Pr}^{1 / 3} \sqrt{\frac{c}{x}}}{\left[\frac{1}{x U_{e}(x)^{b-1}} \int_{0}^{x} U_{e}(\zeta)^{b-1} d \zeta\right]^{\frac{1}{2}}}
$$

where $\zeta$ is a dummy integration variable representing $x$, and $b=2.95 \operatorname{Pr}^{0.07}$.

Figure 8 shows that the VIST results at the stagnation point agree with the $\operatorname{Re}_{c}=2.42 \times 10^{6}$ Poinsatte case. However, downstream of the stagnation point, the VIST measurements increase and then decrease in a manner similar to the Poinsatte data. The increase in Frossling numbers was unexpected and may indicate an "impingement inviscid core" region created by the new shape of the tunnel sidewalls. However, downsteam of the maximum Frossling number, the Frossling numbers decrease at a rate similar to the Poinsatte data and are larger in value as would be expected given the change from isothermal wall conditions to those of constant flux.

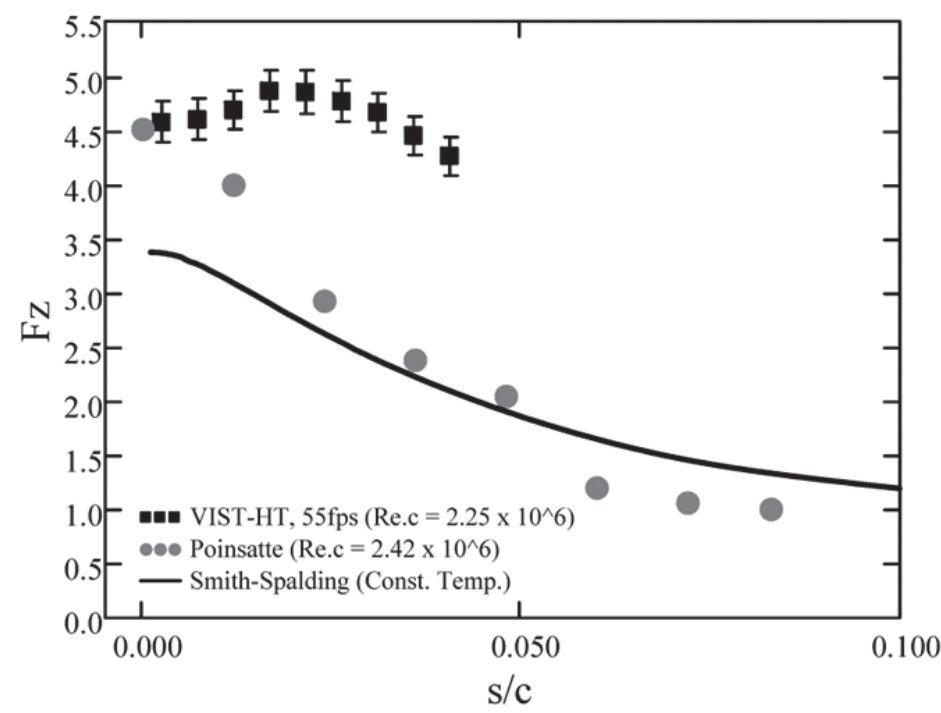

Figure 8. Comparison of VIST Measurements to Isothermal NACA 0012 Measurements of Poinsatte [16]

\section{B. Roughness Convective Enhancement Results}

As noted in Tables 2 and 3, seven surfaces including the smooth surface were tested at three different throat velocities. The six rough surfaces were based on two distinct roughness distributions and constructed using plastic 
hemispheres, plastic cones, or aluminum cones. Because of the lack of a physical airfoil in the tests, the results of the enhancement are presented in terms of Stanton numbers instead of Frossling numbers. Stanton numbers are not dependent on the distance from the stagnation point in mathematical definition and further have the benefit that the Stanton number variation with the flow direction distance reflects behavior similar to the variation expected for skin friction coefficients.

Figure 9 presents the Stanton numbers for the surfaces constructed using the x10x10 distribution compared to the smooth surface results. Each subfigure in Figure 9 groups the surface results by VIST throat velocity. Included in Figure 9 are the predictions for the Stanton numbers based on applying the Smith and Spalding [18] correction to the convection correlation for laminar flow with a constant flux boundary condition.

$$
\mathrm{St}_{\mathrm{x}}=\frac{N u_{x}}{\operatorname{Re}_{x} \cdot \operatorname{Pr}}=\frac{0.453 \mathrm{Re}_{x}^{-1 / 2} \operatorname{Pr}^{-2 / 3}}{\left[\frac{1}{x U_{e}(x)^{b-1}} \int_{0}^{x} U_{e}(\zeta)^{b-1} d \zeta\right]^{\frac{1}{2}}}
$$

Figure 9 demonstrates several important phenomena. First, Figure 9 shows that the smooth surface results compare well with the Smith and Spalding predictions of Eq. (11). Second, for the x10x10 distribution, the measured convection from the plastic cones and plastic hemispheres both increase to a maximum at the location of the where the roughness elements reach maximum heights and then decay. At the maximum values, the convection coefficients are $200 \%-250 \%$ of the smooth surface convection coefficients. While the plastic cones generally exhibit slightly higher convection coefficients, the convection from both plastic x10x10 distributions are comparable.

Another interesting aspect of Figure 9 is that downstream of the location of maximum convection and roughness, the Stanton numbers approach the laminar predictions of Eq. (11) as if the flow were attempting to relaminarize in response to the very high local acceleration rates. Hot-wire traces taken downstream of the roughness x10x10 cones and hemispheres indicated that turbulent flow exist downstream of the roughness region; however, the relaminarization process could not be verified.

Figure 9 also shows that the aluminum cone x10x10 surface exhibits much higher convection coefficient values than either plastic surface with the exception of just at the location of the maximum roughness height. However, the aluminum results do indicate that the lack of thermal resistance (very high thermal conductivity values) are smearing the results. That is, at the stagnation point, longitudinal (in the flow direction) conduction effects make the measured coefficients appear much higher than the values found on the plastic surfaces and the values predicted using Smith and Spalding correlation.

Figure 10 presents the Stanton numbers for the surfaces constructed using the x10x25 distribution compared to the smooth surface results. As is the case for Figure 9, each subfigure in Figure 10 groups the surface results by VIST throat velocity. Comparing the plastic $\mathrm{x} 10 \mathrm{x} 25$ cases to the plastic $\mathrm{x} 10 \mathrm{x} 10$ cases, the maximum convection rates on the $\times 10 \times 25$ surfaces appear much farther downstream because the location of maximum roughness occurs much farther downstream. Unlike the plastic $\times 10 \times 10$ cases, the $\times 10 \times 25$ cases do show that for one velocity cases, the $7.62 \mathrm{~m} / \mathrm{s}(25 \mathrm{ft} / \mathrm{s})$ case, the plastic cones promote higher convection rates than the plastic hemispheres. For the slowest velocity, the best explanation is that the increased blockage of the hemispherical elements decreases energy of the fluid interacting with the roughness elements. As the throat velocity increases, the momentum of the fluid is able to bring it closer to the hemispherical roughness elements such that significant differences do not exist between the x $10 \times 25$ plastic cones and hemispheres. For the $12.19 \mathrm{~m} / \mathrm{s}(40 \mathrm{ft} / \mathrm{s})$ and $16.76 \mathrm{~m} / \mathrm{s}(55 \mathrm{ft} / \mathrm{s})$ cases, the maximum convection rates are between $300 \%$ and $350 \%$ of the laminar predictions. For the lowest throat velocity, the 7.62 $\mathrm{m} / \mathrm{s}(25 \mathrm{ft} / \mathrm{s})$ case, the plastic cone surface exhibits a convection rate just below $400 \%$ of the laminar Stanton number prediction.

Figure 10 also demonstrates that the $\times 10 \times 25$ aluminum cones, like the $\times 10 \times 10$ aluminum cones, are affected by internal conduction in that the stagnation point Stanton numbers are much higher than predicted using the laminar Smith and Spalding correlation. However, Figure 10 demonstrates that once the roughness levels become significant on the $\times 10 \times 25$ aluminum surface, the convection rates increase significantly until the Stanton numbers reach near-constant or slightly-decreasing levels. Recalling the Stanton number definition of Eq. (7), $\mathrm{St}=h /\left(\rho c_{p} U_{e}\right)$, the near constant values indicate that the convection rates are increasing at a rate proportional to the increases in freestream velocity for the aluminum surface. 

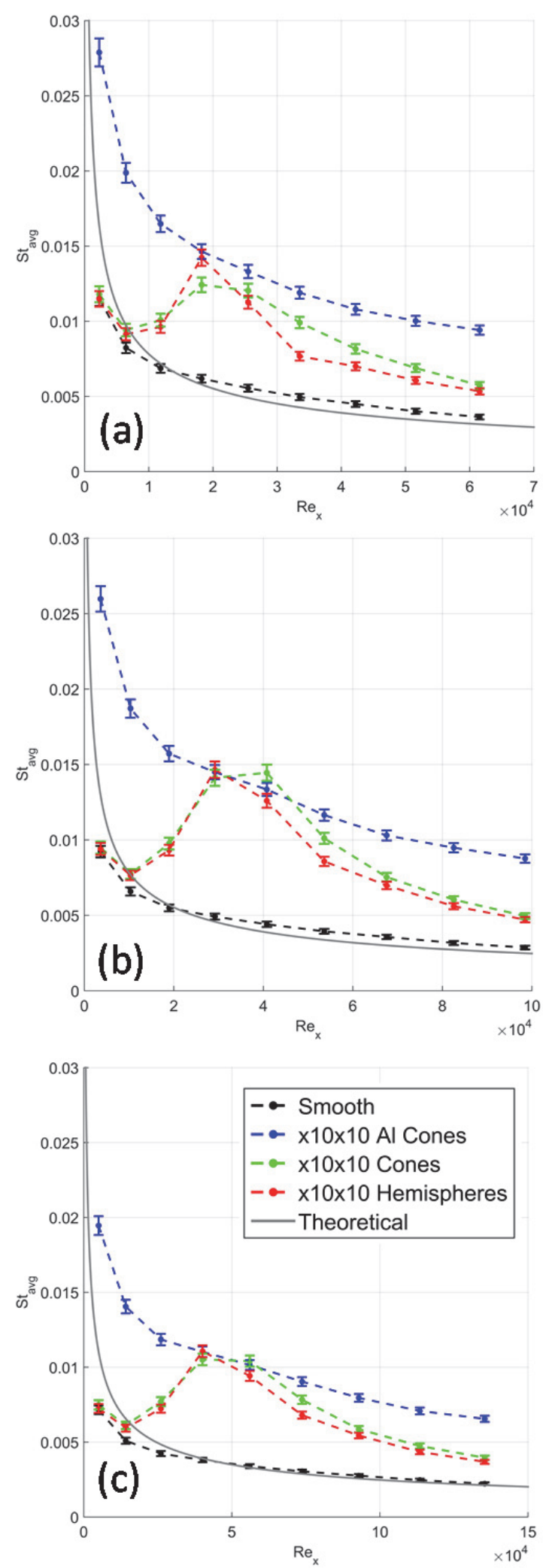

Figure 9. Measured Stanton Numbers for the x10x10 distribution: (a) $7.62 \mathrm{~m} / \mathrm{s}(25 \mathrm{ft} / \mathrm{s})$, (b) 12.19 $\mathrm{m} / \mathrm{s}(40 \mathrm{ft} / \mathrm{s})$, and (c) $16.76 \mathrm{~m} / \mathrm{s}(55 \mathrm{ft} / \mathrm{s})$
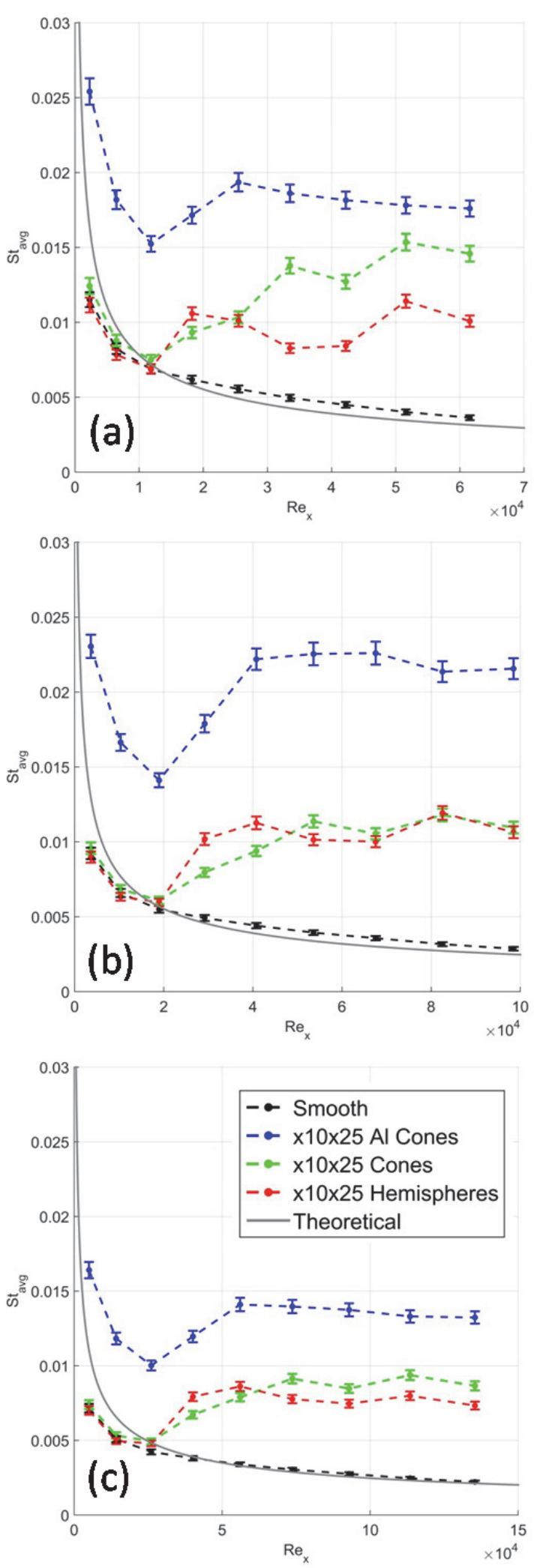

Figure 10. Measured Stanton Numbers for the x10x25 distribution: (a) $7.62 \mathrm{~m} / \mathrm{s}(25 \mathrm{ft} / \mathrm{s})$, (b) 12.19 $\mathrm{m} / \mathrm{s}(40 \mathrm{ft} / \mathrm{s})$, and (c) $16.76 \mathrm{~m} / \mathrm{s}(55 \mathrm{ft} / \mathrm{s})$

13

American Institute of Aeronautics and Astronautics 
The intent of using aluminum surfaces was to replicate the near isothermal surface caused by the phase change of an ice surface. The results of Figures 9 and 10 indicate that because the aluminum thermal conductivity is so high and the plates are so large, the longitudinal and spanwise conduction effects are extremely important. In hindsight, if the wall-normal isothermal effects must be considered, the best way to accomplish this is to machine short strips (in the x-direction) of the surface and separate the strips with insulators to inhibit the flow-direction conduction. The most relevant findings from this study that can be inferred for the aluminum surfaces are 1) for the $\mathrm{x} 10 \mathrm{x} 10$ the convection rates from the aluminum surface at the point of maximum roughness is very similar to the convection rates from the surfaces with plastic elements at the same surface location and 2) for the x10x25 surface, for which the point of maximum roughness occurs much further downstream and experiencing a taller boundary layer, the convection rates from the aluminum surface are much higher than the convection rates on the plastic surfaces at the same surface location. These two findings are used to infer that roughness element conduction is more important when the roughness elements are interacting with larger boundary layers.

\section{Conclusion}

As part of an ongoing effort to examine the effects of ice roughness on convective enhancement in aircraft icing events, this study examined such convective enhancement in the stagnation region, or the leading $2 \%$ chord, of a 21 in. NACA 0012 which was tested in the IRT at NASA Glenn. Using ice roughness distributions modeled from a real ice shape generated in the Icing Research Tunnel at NASA Glenn Research Center, experiments were performed in the Vertical Icing Studies Tunnel at NASA Glenn Research Center. Because of the difference between the airfoil used in the IRT and the test section of the VIST, scaling issues were encountered. Based on the two different roughness element distributions, rough surfaces were created using plastic hemispheres, plastic cones, and aluminum cones. Infrared camera and thermocouple measurements were used to determine convective heat transfer rates from the surfaces under three flow conditions.

The primary conclusions of the study are:

1) For the $\times 10 \times 10$ distributions, the convection rates from the plastic cones was not substantially different from the convection rates from the plastic hemispheres,

2) The convection rates for the aluminum $\times 10 \times 10$ are not significantly different from the rates on the plastic $\mathrm{x} 10 \mathrm{x} 10$ distributions at the point of the maximum roughness heights,

3) For the $\times 10 \times 25$ distributions, the convection rates from the plastic cones was significantly higher than the plastic hemispheres only for the lowest throat velocity tested,

4) The convection rates for the aluminum $\times 10 \times 25$ surface are significantly higher than the plastic distributions at the point of maximum roughness heights indicating the roughness thermal conductivity may be more important when the boundary layers are taller relative to the roughness height, and

5) While the aluminum surfaces were intended to simulate the near-isothermal condition imposed by the phase change occurring on an iced airfoil surface, lateral and longitudinal conduction effects are significant in the current experimental results. The results presented are still important in that they may be used to infer the importance of the local fluid temperature within the boundary layer, however, the results are not expected to reflect the physics of isothermal rough surfaces in stagnation region flows.

The results of the study provide significant insight into the physics of convection enhancement caused by icing roughness. Further, the comparison of plastic cones and hemispheres indicate that either shape may be appropriate models for real roughness formed in the stagnation regions of airfoils exposed to supercooled icing conditions.

\section{Acknowledgments}

The study was performed under the NASA Internship, Fellowships, and Scholarships Program and the Lewis Educational and Research Collaborative Internship Program at NASA Glenn Research Center. The assistance of Mr. Robert Clark and Mrs. Katelyn McCormick at NASA GRC and Mr. Ashley Orr at Baylor University is greatly appreciated. The assistance of Dr. Donald P. McErlean and Mr. Robert Blenden of L3 Integrated Systems in Waco, TX in the CNC routing of the Plexiglas test plate base is also greatly appreciated. Finally, the work of fellow graduate students Mr. Logan Tecson, Mr. Charles P. Brown, Mr. Christopher Walker, and Mr. Tim Shannon on previous studies contributing to this project has been invaluable. Any opinions presented in this paper are those of the authors and do not reflect the views of NASA or the United States government. 


\section{References}

${ }^{1}$ Wright, W., "User's Manual for LEWICE Version 3.2,” NASA/CR-2008-214255, Nov. 2008.

${ }^{2}$ Dipprey, D. F., and Sabersky, R.H., (1963), "Heat and Momentum Transfer in Smooth and Rough Tubes at Various Prandtl Numbers," Int. J. of Heat and Mass Transfer, Vol. 6, 329-353.

${ }^{3}$ Shannon, T.A. and McClain, S.T., (2015), "Convection from a Simulated NACA 0012 Airfoil with Realistic Ice Accretion Roughness Variations," SAE 2015 International Conference on Icing of Aircraft, Engines, and Structures, June 22-26, Prague, Czech Republic.

${ }^{4}$ Tecson, L. and McClain, S.T., (2013), "Convective Enhancement of Surfaces with Realistic Ice Roughness Distributions," 5th AIAA Atmospheric and Space Environments Conference, 24-27 June, San Diego, CA, AIAA-2013-3060.

${ }^{5}$ Walker, C.W., McClain, S.T. and Shannon, T.A., (2014), "Convection from Ice Roughness with Varying Flux Boundary Conditions," 6th AIAA Atmospheric and Space Environments Conference, 16-20 June, Atlanta, GA, AIAA-2014-2463.

${ }^{6}$ Anderson, D. N., and Shin, J., (1997), "Characterization of Ice Roughness from Simulated Icing Encounters," NASA TM107400.

${ }^{7}$ Anderson, D. N., Hentschel, D. B., and Ruff, G. A., (1998), "Measurement and Correlation of Ice Accretion Roughness," NASA CR-2003-211823.

${ }^{8}$ Shin, J., (1994), “Characteristics of Surface Roughness Associated With Leading Edge Ice Accretion,” NASA TM-106459.

${ }^{9}$ Hughes, M.T., McClain, S.T., Vargas, M., and Broeren, A., (2015), "Convective Enhancement of Icing Roughness in Stagnation Region Flows," 7th AIAA Atmospheric and Space Environments Conference, June 22-25, Dallas, TX, AIAA-20153021.

${ }^{10}$ White, E. B. and Oliver, M. J., (2005), “Experiments on Surface Roughness Effects in Ice Accretion,” Presented at the AIAA 4th Theoretical Fluids Meeting, June 22-25, 2005, Toronto, ON, AIAA-2005-5190.

${ }^{11}$ McClain, S.T. and Kreeger, R.E., (2013), “Assessment of Ice Shape Roughness Using a Self-Organizing Map Approach," Presented at the 5th AIAA Atmospheric and Space Environments Conference, June 24-27, 2013, San Diego, CA, AIAA-2013-2546.

${ }^{12}$ Tecson, L. and McClain, S.T., (2013), "Modeling of Realistic Ice Roughness Element Distributions to Characterize Convective Heat Transfer," 5th AIAA Atmospheric and Space Environments Conference, 24-27 June, San Diego, CA, AIAA2013-3059.

${ }^{13}$ Hughes, M., "Convective Enhancement on Airfoils Due to Ice Roughness Elements in Stagnation Region Flows,” M.S. Thesis, Baylor University, December 2015.

${ }^{14}$ Coleman, H. W. and Steele, W. G., (1999), Experimentation and Uncertainty Analysis for Engineers, Second Edition, John Wiley and Sons, Inc.

${ }^{15}$ Kline, S. J., and McClintock, F. A., (1953), "Describing Uncertainties in Single-Sample Experiments," Mechanical Engineering, Vol. 75, pg 3-8.

${ }^{16}$ Poinsatte, P.E., "Heat Transfer Measurements from a NACA 0012 Airfoil in Flight and in the NASA Lewis Icing Research Tunnel," M.S. Thesis, The University of Toledo, June 1989.

${ }^{17}$ Poinsatte, P. E., Van Fossen, G. J., Newton, J. E., and De Witt, K. J., "Heat Transfer Measurements from a NASA 0012 Airfoil," Journal of Aircraft, Vol. 28, No. 12, 1991, pp. 892-898.

${ }^{18}$ Smith, A.G., and Spaulding, D.B., (1958), "Heat Transfer in a Laminar Boundary Layer with Constant Fluid Properties and Constant Wall Temperature,” J. Roy. Aero. Soc., Vol. 62, pg 60-64. 